\title{
A Suécia no Novo Milênio: os Direitos Humanos sob a Nova Ordem Mundial
}

\author{
Suecia en el nuevo milenio: los derechos humanos bajo el nuevo orden \\ mundial
}

\section{Sweden in the New Millennium: Human Rights under the New World Order}

Felipe de Andrade Nunes Pereira Zamana ${ }^{1}$

\begin{abstract}
Resumo
Este artigo busca apontar informações sobre o fenômeno migratório na Suécia envolvendo as violações de direitos humanos no país. Trata-se de uma pesquisa explicativa, realizada através de uma abordagem qualitativaquantitativa, englobando elementos bibliográficos, documentais e estatísticos à análise. Utiliza-se também o método indutivo, com o intuito de contrapor o discurso instituído pela mídia e orientar o leitor a um viés divergente do abordado pela agenda política do Primeiro Mundo, atribuindo, juntamente das informações coletadas, um caráter humanitário ao contexto em foco. Os resultados apontam para a ausência de comprovação científica envolvendo a correlação entre as comunidades de imigrantes e o aumento da criminalidade ou o desequilíbrio econômico que ameaça o Estado de bem-estar social sueco. Ademais, evidencia-se uma série de graves ameaças aos direitos dos grupos minoritários no país, envolvendo inclusive as comunidades tradicionais Sami.
\end{abstract}

Palavras-chave: Direitos Humanos; Imigração; Sociedade; Suécia.

\section{Resumen}

Este artículo busca apuntar informaciones sobre el fenómeno migratorio en Suecia involucrando las violaciones de derechos humanos en el país. Se trata de una investigación explicativa, realizada a través de un abordaje cualitativo cuantitativo, englobando elementos bibliográficos, documentales y estadísticos al análisis. Se utiliza también el método inductivo, con el propósito de contraponer el discurso instituido por los medios y orientar al lector a un sesgo divergente del abordado por la agenda política del Primer Mundo, asignando, junto a las informaciones recolectadas, un carácter humanitario al contexto en foco. Los resultados apuntan a la ausencia de comprobación científica que involucra la correlación entre las comunidades de inmigrantes y el aumento de la criminalidad o el desequilibrio económico que amenaza el Estado de bienestar social sueco. Además, se evidencia una serie de graves amenazas a los derechos de los grupos minoritarios en el país, involucrando incluso a las comunidades tradicionales Sami.

Palabras clave: Derechos Humanos; la inmigración; la sociedad; Suecia.

\begin{abstract}
This article seeks to point out information about the migratory phenomenon in Sweden involving human rights violations in the country. It is an explanatory research, carried out through a qualitative-quantitative approach, encompassing bibliographical, documentary and statistical elements to the analysis. The inductive method is also used in order to counter the discourse instituted by the media and to guide the reader to a divergent bias that is addressed by the First World political agenda, attributing, together with the information collected, a humanitarian character to the context in focus. The results point to the absence of scientific evidence involving the correlation between immigrant communities and increased crime or economic imbalance that threatens the
\end{abstract}

\footnotetext{
${ }^{1}$ Bacharel em Direito pela Universidade Federal do Rio Grande (FURG), Rio Grande, RS; Brasil;
} felipedean@gmail.com 
Swedish welfare state. In addition, a number of serious threats to the rights of minority groups in the country, including the traditional Sami communities, are evident.

Keywords: Human Rights; Immigration; Society; Sweden.

\section{Introdução}

A Suécia é um dos países que operam em situação de vanguarda na proteção dos Direitos Humanos no cenário internacional, possuindo um ordenamento jurídico robusto sobre o assunto. Com o título de Estado de bem-estar social efetivamente conquistado durante a década de 1950, o pequeno país nórdico de apenas 9 milhões de habitantes se tornou referência internacional por sua elevada qualidade de vida, aliada a uma economia competitiva, atrativa ao mercado global.

No entanto, com a crise humanitária paulatinamente instituída pelo Ocidente nos países em desenvolvimento - processo do qual a Suécia ativamente participa-, sua política nacional tem sido modulada progressivamente, frente à rejeição popular a grupos de refugiados. Isto pois desde o fim da Segunda Guerra Mundial, com a escalada da tensão nos países do Oriente Médio, os países da região diretamente atingidos pela política belicista norte-americana e europeia sofrem de um maciço êxodo, oriundo dos conflitos locais.

As potências globais, assim, detêm todos os elementos necessários ao regramento da nova ordem mundial, sendo desta forma capazes de proporcionar a coerção necessária à manutenção do poder supranacional. São tais elementos: poderio bélico, econômico e de influência. O primeiro diz respeito ao modo de imposição por meio da violência e da guerra; o segundo é capaz de afetar diretamente o sistema econômico global, fragilizando a estabilidade social; o terceiro, por sua vez, e o mais comum, se opera por meio dos sistemas de difusão de informações, aproveitando-se o fenômeno da globalização para a manipulação da verdade.

Entretanto, ao vislumbrar os impactos da imigração, não se pode negar a situação dos povos que são recebidos, a contragosto, nos países anfitriões. A exemplo da Suécia, se busca compreender de que maneira o governo local tem suprido a crescente demanda social da população migratória, e que medidas tem tomado para incluí-la na sociedade sueca, tendo como parâmetros os valores constitucionalmente garantidos e o notável garantismo instituído, que tornou o país famoso por ser sobretudo igualitário.

\section{O Constitucionalismo sueco}


Ao classificar a Constituição sueca, é possível observar que se trata de um documento: formal quanto à supremacia; escrita quanto à forma; dogmática quanto ao modo de elaboração; promulgada quanto à origem; rígida quanto à estabilidade; analítica quanto à extensão e dirigente quanto à função. Entretanto, para que se façam entender os princípios constitucionais suecos, a organização do Estado e os objetivos de sua administração, é mister recorrer às quatro Leis Fundamentais suecas (Sveriges grundlagarna), que compõem sua Constituição. Os princípios encontram-se descritos sobretudo no primeiro capítulo do Instrumento de Governo (IG), e complementados por seus demais artigos.

Capítulo 1: Princípios básicos da forma de governo.

Art. 1. Todo poder público na Suécia procede do povo. A democracia sueca é fundada na livre formação de opinião e no sufrágio universal e igualitário. É exercido através da forma de governo representativa e parlamentar, e por meio da autonomia local. O poder público é exercido conforme a lei $(2016$, p. 65, tradução nossa). ${ }^{2}$

No artigo primeiro, faz-se menção aos princípios da democracia, igualdade, autonomia e legalidade, sendo a democracia dividida em dois elementos, quais sejam: a livre formação de opinião e o sufrágio universal e igualitário. Os princípios da liberdade e igualdade, por sua vez, há muito tempo regram a sociedade sueca. Assim, o fluxo de valores da sociedade à Constituição dá sentido à concepção hegeliana de Estado, que é definida como "a realidade em ato da ideia moral objetiva, o espírito como vontade substancial revelada, clara para si mesma, que se conhece e se pensa, e realiza o que sabe e porque sabe”. (HEGEL, 1997).

Além disso, a representatividade e o sistema de governo parlamentar também são considerados características fundamentais do governo sueco. Isso surge sobretudo como forma de evitar possíveis instabilidades em seu sistema político, tendo em vista o passado tortuoso ao qual se subordinou a política sueca em face do poder real.

Os princípios da liberdade e dignidade são versados no extenso artigo $2^{\circ}$ do IG. A preocupação com o bem-estar do cidadão aparece como objetivo principal do poder público, que deve promover meios para o desenvolvimento saudável dos indivíduos. O dispositivo também assegura o direito ao trabalho, moradia, educação, assistência e previdência sociais, desenvolvimento sustentável, proteção do meio ambiente, direito das crianças, combate à discriminação de qualquer natureza e promoção de oportunidades à população Sami.

\footnotetext{
${ }^{2}$ Chapter 1. Basic principles of the form of government. Art. 1. All public power in Sweden proceeds from the people. Swedish democracy is founded on the free formation of opinion and on universal and equal suffrage. It is realised through a representative and parliamentary form of government and through local self-government. Public power is exercised under the law.
} 
$\mathrm{O}$ artigo $3^{\circ}$ da Constituição sueca determina os documentos que a compõem. Por ser uma Constituição escrita, porém esparsa, é dividida em quatro documentos diferentes: o Instrumento de Governo (Regeringsformen), a Lei do Riksdag (Riksdagsordningen), o Ato de Sucessão (Successiosnorningen) e a Lei de Liberdade de Imprensa (Tryckfrihetsförordningen). O Ato Parlamentar (Riksdagsordningen), por sua vez, não consta dentre os documentos listados, mas tendo em vista sua importância, possui força de lei complementar.

Capítulo 1: Princípios básicos da forma de governo.

Art. 3. O Instrumento de Governo, o Ato de Sucessão, a Lei de Liberdade de Imprensa e a Lei Fundamental de Liberdade de Expressão são as leis fundamentais do Reino (2016, p. 65, tradução nossa). ${ }^{3}$

É necessário observar que não há separação dos poderes no constitucionalismo sueco, tendo em vista que segue o modelo monista. Assim, o maior cargo público que um cidadão pode ocupar abaixo do Rei é o de Presidente do Parlamento (Riksdagens talman). O cidadão elege o Riksdag, que realiza eleições para presidente. Este, por sua vez, nomeia o Primeiro Ministro. Se aprovado por maioria absoluta no parlamento, o então primeiro ministro nomeia os demais ministros.

Assim sendo, uma vez monista, o modelo de governo sueco necessita que o ministro da justiça faça a nomeação dos juízes de direito. Vale ressaltar que, muito embora o Ministro da Justiça seja responsável pelo sistema judiciário, este não possui permissão constitucional para intervir nas decisões proferidas pelos juízes (SUÉCIA, 2015). Segundo o Instrumento de Governo:

Capítulo 11 - Administração de justiça Administração de justiça Independente

Art. 3. Nem o Riksdag, ou autoridade pública, pode determinar como um tribunal de direito deve julgar um caso individual, ou até mesmo aplicar a lei em um caso particular. Tampouco pode qualquer autoridade pública determinar como as responsabilidades judiciais devem ser distribuídas entre juízes individuais (2016, p. 90, tradução nossa). ${ }^{4}$

No que diz respeito aos tratados internacionais, os parlamentares se depararam com um impasse: o ingresso da Suécia à União Europeia (UE). Como os termos de ingresso à entidade outorgavam poderes sobre a Suécia além dos desejados, havia o temor de que uma

\footnotetext{
${ }^{3}$ Chapter 1. Basic principles of the form of government. Art. 3. The Instrument of Government, the Act of Succession, the Freedom of the Press Act and the Fundamental Law on Freedom of Expression are the fundamental laws of the Realm.

${ }^{4}$ Chapter 11. Administration of justice. Independent administration of justice. Art. 3. Neither the Riksdag, nor a public authority, may determine how a court of law shall adjudicate an individual case or otherwise apply a rule of law in a particular case. Nor may any other public authority determine how judicial responsibilities shall be distributed among individual judges.
} 
relação de subordinação do país escandinavo fosse instituída. Assim, decidiram transferir o poder de decisão de determinadas matérias à UE com a condição de que fossem protegidos pela entidade os mesmos direitos resguardados em seu Instrumento de Governo, e na Convenção Europeia para Proteção de Direitos Humanos e Liberdades Fundamentais. Assim, houve a emenda do IG em 2003, versando sobre acordos e tratados em seu artigo $10^{\circ}$ do primeiro capítulo:

Capítulo 1: Princípios básicos da forma de governo.

Art. 10. A Suécia é um membro da União Europeia. A Suécia também participa em cooperação internacional na estrutura das Nações Unidas e do Conselho Europeu, e em outros contextos $\left(2016\right.$, p. 66 , tradução nossa). ${ }^{5}$

\subsection{Direitos e Liberdades fundamentais}

Em consonância com os princípios do primeiro capítulo, relativos à forma de governo, os direitos e liberdades fundamentais são dispostos no IG taxativamente. O Artigo $1^{\circ}$ do segundo capítulo busca dispor sobre os direitos de opinião. Este, por sua vez, subdivide-se em outras liberdades fundamentais, tais como liberdade de expressão, liberdade de informação, liberdade de assembleia, liberdade de manifestação, liberdade de associação e liberdade de crença. É necessário ressaltar que os direitos de opinião operam em consonância com a Lei de Liberdade de Imprensa. O primeiro artigo também versa sobre o princípio da publicidade, a ser tratado na lei de Liberdade de Imprensa.

Os direitos da comunidade $\mathrm{LGBT}^{6}$ também constam entre o rol de direitos consagrados pela sociedade sueca, colocando o país em posição de vanguarda entre os demais de cultura ocidental. O Riksdag reconhece desde 1944 relacionamentos sexuais entre pessoas do mesmo sexo, e foi o primeiro país no mundo a permitir a mudança legal de gênero após a cirurgia de troca de sexo, juntamente com a desclassificação do travestismo como doença, em 1972. O exército sueco é um dos poucos no mundo a permitir o alistamento de homossexuais, o que ocorre desde a década de 70. Entretanto, o casamento entre pessoas do mesmo sexo só foi possível em 2009.

Art. 2. O Poder público deverá ser exercido com respeito ao igual valor de todos e à liberdade e dignidade do indivíduo

(...)

\footnotetext{
${ }^{5}$ Chapter 1. Basic principles of the form of government. Art. 10. Sweden is a member of the European Union. Sweden also participates in international cooperation within the framework of the United Nations and the Council of Europe, and in other contexts.

${ }^{6}$ Sigla que representa a comunidade de lésbicas, gays, bissexuais, transexuais e transgêneros.
} 
As instituições públicas devem promover a oportunidade a todos para que atinjam participação e igualdade na sociedade, e para que os direitos das crianças sejam salvaguardados. As instituições públicas devem combater a discriminação de pessoas baseada em gênero, cor, origem nacional ou étnica, filiação linguística ou religiosa, incapacidade funcional, orientação sexual, idade ou outra circunstância afetando o indivíduo (2016, p. 65 , tradução nossa). ${ }^{7}$

Outros títulos do segundo capítulo dizem respeito à integridade física e liberdade de locomoção (no país é proibida a pena de morte), ao Estado de Direito (princípio da legalidade), à proteção contra discriminação, bem como trata sobre a ação industrial, a proteção da propriedade e o direito ao acesso público, direitos autorais, liberdade de comércio, educação e pesquisa. Além disso, trata também das hipóteses e condições nas quais esses direitos podem ser restringidos pelo poder público.

A preservação dos direitos dos povos nativos da Escandinávia foi resguardada no início da nova Constituição (Instrumento de Governo), embora discretamente. A população Sami constitui uma sociedade indígena que habita os territórios Árticos dos países do Norte, e que usufrui de tratamento igualitário aos suecos na sociedade. Segundo o artigo $2^{\circ}$ do Instrumento de Governo vigente:

Capítulo 1: Princípios básicos da forma de governo.

Art. 2. (...) As oportunidades do povo Sami e de minorias étnicas, linguísticas e religiosas para preservar e desenvolver uma vida cultural e social próprias devem ser promovidas $\left(2016\right.$, p. 65 , tradução nossa). ${ }^{8}$

O exercício de cidadania do povo Sami envolve o direito ao voto nas eleições nacionais, bem como nas eleições do Parlamento Sami (Sametinget). Este parlamento foi instituído em 1993, tendo como característica principal a autonomia; objetiva também a participação do povo Sami na administração da Suécia, visto que não possui funções políticas.

Assim, o Sametinget visa sobretudo representar os interesses do povo Sami na administração nacional. Então, após analisar a extensão de direitos e garantias que a constituição sueca busca abranger, é possível notar forte engajamento quanto à proteção de grupos de vulnerabilidade, tanto social quanto econômica. Nota-se, ademais, a clara intenção do legislador na promoção de um Estado garantista, que começou a tomar forma desde 1870,

\footnotetext{
${ }^{7}$ Art. 2. Public power shall be exercised with respect for the equal worth of all and the liberty and dignity of the individual. (...) The public institutions shall promote the opportunity for all to attain participation and equality in society and for the rights of the child to be safeguarded. The public institutions shall combat discrimination of persons on grounds of gender, colour, national or ethnic origin, linguistic or religious affiliation, functional disability, sexual orientation, age or other circumstance affecting the individual.

${ }^{8}$ Chapter 1. Basic principles of the form of government. Art. 2. (...) The opportunities of the Sami people and ethnic, linguistic and religious minorities to preserve and develop a cultural and social life of their own shall be promoted.
} 
e tornou a Suécia um dos países que ocupam posição de vanguarda no tocante à promoção da igualdade.

\subsection{A proteção constitucional dos Direitos Humanos}

A relação entre a Suécia e os Direitos Humanos tem suas origens desde o início do desenvolvimento de seu estado de bem-estar social (Welfare State), a partir de 1870, e potencializado sobretudo pela abstenção do país na Segunda Guerra Mundial, por suas inovações tecnológicas, abundância de recursos naturais e um período de grande expansão industrial durante a reconstrução da Europa (SANANDAJI, 2011).

Conforme disposto anteriormente, a Constituição sueca apresenta mutabilidade rígida, o que indica que somente pode ser emendada mediante processo específico previsto em lei, que é mais dificultoso que o relativo às leis ordinárias. Os tratados internacionais, portanto, possuem duas formas de serem incorporados no ordenamento jurídico sueco, sendo estes incorporação e transposição. O primeiro é a indicação expressa na lei ou outro instrumento legal de que o dispositivo do tratado é diretamente aplicável na Suécia, enquanto que o segundo se refere à tradução do tratado e sua inclusão ao rol normativo sueco. Destes, a técnica mais utilizada é a transposição (SANDBERG, 2002).

A Declaração Universal de Direitos Humanos (DUDH) constitui apenas um dos diversos documentos ratificados pelo país que guardam relação com Direitos Humanos. Portanto, conforme a Suécia se torna mais presente nos tratados de direitos sociais, menor é a necessidade do legislador de suprir possíveis lacunas normativas sobre o tema. Os direitos e garantias fundamentais expostos na DUDH são exemplo disso, tendo em vista que atendem a vários dos princípios e direitos dispostos nos capítulos 1 e 2 do IG, tais como liberdade (de locomoção, pensamento, opinião e religião), igualdade, dignidade, residência, proibição de castigos físicos e discriminação.

Além da Organização das Nações Unidas (ONU), a Suécia também é membro de outras entidades que guardam forte relação com os Direitos Humanos, tais como a Convenção Europeia para Direitos Humanos (CEDH), o Conselho Europeu, a Organização Internacional do Trabalho (OIT) e a Organização para a Segurança e Cooperação na Europa (OSCE). É também membro ativo de tribunais e cortes internacionais, como o Tribunal Penal Internacional (TPI) e o Tribunal Europeu de Direitos Humanos (TEDH). No âmbito interno, a Suécia também abriga diversas Organizações Não Governamentais que visam proteger direitos humanos, observando a administração local. Através de suas Ouvidorias 
(ombudsmän), é possível realizar denúncias anônimas em caso de violações a direitos e garantias fundamentais, o que facilita a descoberta de irregularidades na gestão pública ou entre particulares.

Portanto, para que se façam efetivar, os Direitos Humanos na Suécia são regidos pelos seguintes princípios, conforme a Comunicação do Governo 2003/04:20:

A Suécia buscará consolidar os princípios nos quais baseiam-se as atividades internacionais sobre Direitos Humanos:

- É legítimo reagir - A Suécia pode e deve exercer influência sobre outros países para que respeitem os direitos humanos.

- Direitos Humanos são universais - aplicam-se a todas as pessoas, sobre todo o planeta, independentemente de país, cultura ou situação específica.

- Os Direitos Humanos se aplicam aos indivíduos; sua proteção é de responsabilidade dos governos.

- Os Direitos Humanos são indivisíveis - todos os direitos são importantes e interdependentes. (2003, p.5, tradução nossa). ${ }^{9}$

O Exercício da influência sobre os outros países, conforme descrito no rol de princípios, não deve, no entanto, violar o disposto na Carta das Nações Unidas, que estabelece o princípio da não-intervenção nos casos de violação a Direitos Humanos. A influência se dará, no entanto, mediante a participação ativa da Organização das Nações Unidas e das Cortes Internacionais para a resolução pacífica dos conflitos e estabelecimento da paz universal.

Entretanto, apesar do princípio da não-intervenção, países com alto poderio bélico tendem a elevar as tensões internacionais, mediante o emprego de forças militares em territórios considerados hostis. O Nobel da Paz, ex-presidente Barack Obama, foi exemplo de uma das mais agressivas gestões geopolíticas da América em "tempos de paz", realizando centenas de ataques com aeronaves não tripuladas. ${ }^{10} \mathrm{~A}$ intervenção russa na Ucrânia, também atenta para a impotência da ONU na resolução pacífica dos conflitos estabelecidos entre grandes potências bélicas.

A Suécia, embora se destaque na comunidade internacional no que se refere ao resguardo normativo dos Direitos Humanos, promove sérias contradições ao passo que

\footnotetext{
${ }^{9}$ Sweden will seek to reinforce the principles on which international human rights activities are based:

- It is legitimate to react - Sweden can and should exert influence on other countries to respect human rights.

- Human rights are universal - they apply to all persons, all over the world, irrespective of country, culture or specific situation.

- Human rights apply to individuals; their protection is the responsibility of governments.

- Human rights are indivisible - all rights are important and mutually dependent.

${ }^{10}$ De acordo com a New America Foundation, enquanto o president George W. Bush, durante sua administração, ordenou entre 45 e 50 ataques com drones, matando 477 pessoas, Barack Obama determinou 316 ataques com drones que eliminaram 2.363. (BANDEIRA, p. 92).
} 
exporta, em enormes quantidades, armamentos e equipamentos bélicos a outros países. A empresa sueca SAAB, produtora de segurança e defesa aeroespacial, ocupou em 2016 o $30^{\circ}$ lugar no ranking das maiores indústrias bélicas do mundo, conforme o Instituto de Pesquisa de Paz Internacional de Estocolmo (SIPRI). ${ }^{11} \mathrm{O}$ governo brasileiro, inclusive, chegou a anunciar em 2013 a compra de 36 caças Gripen NG da empresa sueca, sob o valor de 4,5 bilhões de dólares, sob a justificativa de se reforçar a frota da Força Aérea Brasileira. ${ }^{12}$

Muito embora sua última guerra declarada tenha ocorrido há mais de 200 anos, em 1814 na Campanha Contra a Noruega (Fälttåget mot Norge), a Suécia realizou intervenções militares também na Guerra do Talibã (como parte da Operação das Nações Unidas no Congo) na Guerra Civil Líbia (como parte da Força de Proteção das Nações Unidas), visando a promoção da paz. Ocorre que o artigo 2, VII da Carta das Nações Unidas, não prejudica a leitura do artigo 42, que autoriza a realização de intervenções militares mediante prévio consentimento do Conselho de Segurança. Segundo o corpo do artigo, ipsis litteris:

\begin{abstract}
Artigo 42: No caso de o Conselho de Segurança considerar que as medidas previstas no Artigo 41 seriam ou demonstraram que são inadequadas, poderá levar e efeito, por meio de forças aéreas, navais ou terrestres, a ação que julgar necessária para manter ou restabelecer a paz e a segurança internacionais. Tal ação poderá compreender demonstrações, bloqueios e outras operações, por parte das forças aéreas, navais ou terrestres dos Membros das Nações Unidas (1945, p. 30).
\end{abstract}

O Conselho de Segurança da ONU é composto por quinze países-membros, onde cinco destes são permanentes e dotados de poder de veto, quais sejam: Estados Unidos, Rússia, China, Reino Unido e França, A Suécia é um dos dez membros temporários do Conselho de Segurança, o que significa que possui um mandato de dois anos a ser cumprido, cedendo seu lugar a outro país após o período. As resoluções do Conselho de Segurança são aprovadas por maioria de 9 dos quinze possíveis votos, caso não haja veto. O poder de veto indica o poder que os membros permanentes possuem de impedir a aprovação das resoluções do Conselho, sendo necessário o veto de apenas um país para que ocorra. Evidente, portanto, a hegemonia do poder deliberativo do Conselho.

\title{
3. O relatório de Direitos Humanos da Suécia
}

\footnotetext{
${ }^{11}$ Disponível em <https://www.sipri.org/sites/default/files/2017-12/fs_arms_industry_2016.pdf>. Acessos em 10 ago. 2018

${ }^{12}$ Disponível em <http://www.fab.mil.br/noticias/mostra/30389/TECNOLOGIA\%20-

$\% 20$ Novo $\% 20$ modelo\%20do\%20Gripen\%20\%C3\%A9\%20testado\%20na\%20Su\%C3\%A9cia>. Acessos em 10 ago. 2018
} 
Seguindo a lógica da mútua vigilância, desenvolveram-se técnicas e estratégias para o resguardo dos direitos humanos, como é o caso do Relatório dos Países sobre Direitos Humanos, emitido pelo Departamento de Estado dos Estados Unidos. Nele, são denunciadas violações cometidas pela Suécia, conforme disposto a seguir:

\begin{abstract}
Os principais abusos aos Direitos Humanos incluíram discriminação social e incidentes de violência contra estrangeiros, particularmente sobre o grande número de migrantes que chegou ao país desde 2015, e membros de minorias étnicas e religiosas, e abusos domésticos de mulheres e crianças. Autoridades sujeitaram uma alta porcentagem de presos provisórios a períodos extensos em isolamento e limitaram seu acesso a visitantes, correspondência e exercícios $\left(2016\right.$, p. 1 , tradução nossa). ${ }^{13}$
\end{abstract}

O documento simboliza uma forma de observação da comunidade internacional à política interna sueca, orientando sua atuação política, sobretudo de forma a evitar transgressões aos tratados previamente assinados. Assim, poderá o documento significar uma forma de contenção de possíveis excessos do poder público.

A Suécia é, como já dito, é signatária dos mais diversos tratados e documentos referentes a direitos humanos, o que de certo facilita a cobrança por meio das entidades responsáveis de medidas de efetivação destes direitos. Sobre a forma como a sociedade percebe estes indivíduos, o Relatório de Direitos Humanos de 2017 inclui, logo em seu resumo, denúncia de tratamento desigual e violento por parte dos cidadãos em desfavor da população de imigrantes. Conforme o documento:

As questões mais importantes de direitos humanos incluíram ameaças de violência antissemitas e atentados com bombas contra imigrantes, que as autoridades investigaram e processaram $\left(2017\right.$, p.1, tradução nossa) ${ }^{14}$

É necessário, no entanto, afirmar que a discriminação contra populações estrangeiras já vinha sendo denunciada, inclusive por relatórios anteriores a 2010. A participação de grupos neonazistas no processo de violência contra grupos minoritários no país eleva cada vez mais o clima de tensão.

\title{
4. A política de guerra americana e seus reflexos nos países nórdicos
}

\footnotetext{
${ }^{13}$ The main human rights abuses included societal discrimination and incidents of violence against foreigners, particularly the large numbers of migrants who arrived since 2015 and members of ethnic and religious minorities, and domestic abuse of women and children. Authorities subjected a high percentage of pretrial detainees to extended periods in isolation and limited their access to visitors, mail, and exercise.

${ }^{14}$ The most significant human rights issues included anti-Semitic threats of violence and attempted bomb attacks on immigrants, which the authorities investigated and prosecuted
} 
Estabelecendo uma análise, em paralelo, da situação vivida no Oriente Médio, com a política externa das principais potências europeias e dos Estados Unidos, é possível observar uma evidente relação entre a economia de guerra que move o maquinário capitalista e a crise humanitária que afeta os países cujo fluxo migratório é mais intenso. Países cuja situação democrática é mais instável tendem a ser mais atingidos no processo de instauração da nova ordem mundial, liderada pelos Estados Unidos. Conforme argumenta Moniz Bandeira, em sua obra A Desordem Mundial:

\begin{abstract}
A pretensão do Barack Obama consistiu, ultima ratio, na petrification of world order, como definiu os escritor Norman Pollack, e implantar a dominação totalitária dos Estados Unidos, a full-spectrum dominance, almejada, ardentemente, desde a decomposição da União Soviética. Com efeito, quase todas as operações de regime change, efetuadas pelos Estados Unidos, visaram a ganhar posições estratégicas e condicionaram guerras ou em busca de mercado ou de acesso a recursos naturais (2016, p. 145).
\end{abstract}

No entanto, cumpre ressaltar que não mais se toleraria a submissão de um Estado a outro como realizado durante a Segunda Guerra Mundial, tendo em vista que o sentimento estabelecido é o de superação da tirania imposta pelos alemães no passado. Atualmente, o artifício utilizado é o da promoção da democracia, sendo esta um sutil subterfúgio às novas intervenções militares em países atrativos à economia global. Logo, com o aval dos seletos membros do Conselho de Segurança da Organização das Nações Unidas, a atuação bélica das grandes potências está livre ao desejo de suas autoridades.

Ocorre que por conta dos conflitos em prol da "democracia" ocidental, milhões de cidadãos dos países onde ocorrem as referidas intervenções são brutalmente massacrados, não só pela guerra propriamente estabelecida, como também pela estigmatização oriunda deste conflito. Assim, duplamente agredidos, ficam estes indivíduos cada vez mais suscetíveis à violência promovida por discursos radicais, a exemplo dos suprematistas.

Assim, o neoconservadorismo norte-americano tem seus reflexos difundidos pelos países interventores no oriente médio. Com a participação dos países europeus na introdução democrática via fórceps no Oriente Médio, o aumento de atentados terroristas em países nos quais a taxa de criminalidade era das mais baixas causa preocupação generalizada nos cidadãos. A própria forma como é visto o terrorismo contrasta com outros fenômenos, por vezes muito mais perigosos, os quais a sociedade por si mesma abraça silenciosamente. Segundo Harari:

Em 2010, enquanto a obesidade e doenças relacionadas a esse mal mataram cerca de 3 milhões de pessoas, terroristas mataram 7697 indivíduos em todo o mundo, a 
maioria deles em países em desenvolvimento.25 Para um estadunidense ou europeu mediano, a Coca-Cola representa um perigo muito mais letal do que a Al-Qaeda. Como, então, terroristas conseguem dominar as manchetes e mudar a situação política em todo o mundo? Provocando nos inimigos uma reação desmedida. Na essência, o terrorismo é um show. Os terroristas encenam um tenebroso espetáculo de violência que captura nossa imaginação e nos transmite a sensação de estar escorregando de volta ao caos medieval. Em consequência, os Estados frequentemente se sentem obrigados a reagir ao teatro do terrorismo com um show de segurança, orquestrando imensas exibições de força, como a perseguição a populações inteiras ou a invasão de países estrangeiros. $\mathrm{Na}$ maioria dos casos, essa reação exacerbada representa um perigo muito maior a nossa segurança do que aquele decorrente de atentados terroristas (2015, p. 22).

Assim, a finalidade do ato terrorista não é a atrocidade por si só, mas sua visibilidade internacionalmente. Em verdade, o que ocorre é uma verdadeira resposta ao massacre ocorrido contra os povos de países, estratégicos economicamente ou em situação de vulnerabilidade ou instabilidade política. Marcia Tiburi (2016) muito dialoga com o entendimento, ao estabelecer o "não lugar", um lugar anti-político criado pelo ódio, ocupado pelo indivíduo que não se adequa ao modelo, e cuja luta é por sobrevivência.

O que se busca, no entanto, não é tornar legítimas as manifestações de violência de grupos terroristas. Há que se notar as várias facetas de uma mesma realidade, por vezes ofuscadas por veículos midiáticos tendenciosos, operando de acordo com os interesses econômicos de sua liderança. Locke, ao dissertar sobre a tirania, estabelece um importante conceito que determina possíveis razões à insurgência no Oriente Médio contra a dominação norte-americana, que acaba por estender-se aos países do continente europeu:

Onde termina a lei começa a tirania, desde que a lei seja transgredida em prejuízo de alguém. Toda pessoa investida de uma autoridade que excede o poder a ele conferido pela lei, e faz uso da força que tem sob seu comando para atingir o súdito com aquilo que a lei não permite, deixa de ser um magistrado; e, como age sem autoridade, qualquer um tem o direito de lhe resistir, como a qualquer homem que pela força invada o direito de outro (1994, p. 208).

A política de extermínio, fundada na lógica da guerra e no neoconservadorismo americano, chancelada ou não pelo Conselho de Segurança da ONU (2016, p. 161), termina por erradicar quaisquer formas de democracia passíveis de implementação nos países-alvo, por mais tímidas que sejam. Isto pois a democracia não constitui elemento exógeno do Estado, sendo, portanto impossível de ser estabelecida mediante submissão a forças supranacionais. Em verdade, a democracia como um todo é observada por diversos meios de expressão, estando sujeita a modulações características das sociedades em particular, variando, portanto, conforme os contextos socialmente estabelecidos. 
Por sua vez, a criminalidade - ponto-chave das discussões políticas na Suécia-, ganha destaque conforme as estatísticas indicam o aumento de crimes violentos como o homicídio, que quase dobrou entre os anos de 2012 e 2017. No entanto, conforme já observado, não há evidências de que os crimes possuam relação com os imigrantes. O próprio governo assume o aumento dos crimes letais, porém desmistifica a relação do aumento da criminalidade com os imigrantes, indicando que segundo a pesquisa do Conselho Nacional Sueco de Prevenção da Criminalidade, embora $13 \%$ da população sueca tenha sido vítima de agressões em 2015, o número permanece igual ao índice de 2005 , onde a quantidade de imigrantes no país era consideravelmente menor..$^{15}$

Entretanto, os resultados na restrição de concessão de asilo aos refugiados já são evidentes. No ano de 2015, quando se registrou o maior número de imigrantes na Suécia, foram recebidas 162.877 aplicações de asilo, enquanto que em 2016 o número caiu para 28.939. Assim, embora desmistifique a relação entre a criminalidade e a intensa imigração ocorrida nos últimos anos, o governo sueco vem tomando medidas restritivas ao movimento migratório no país, a exemplo da redução orçamentária para a imigração, de 40 bilhões de coroas suecas em 2017, para uma previsão de 19,3 bilhões em 2018, reduzindo-se o montante à quantia de 9 bilhões até 2021. ${ }^{16}$

No mesmo ano de 2015, enquanto a Suécia registrava índices históricos de solicitações de asilo, as guerras no oriente médio atingiam 2,5 milhões de pessoas, e dispersavam mais de 430.000. Além disso, 2.880 refugiados se afogavam no Mediterrâneo tentando chegar à Itália. O número de indivíduos forçados a deixar seus lares em todos os países saltava, de 37,5 milhões em 2005 para 65.6 milhões no final de $2016,{ }^{17}$ e milhares de indivíduos eram contrabandeados em barcos para a Europa, em torno de 88.000 em 2014 (BANDEIRA, 2015).

Desta forma, percebe-se um pouco mais a fundo a amplitude da catástrofe humanitária. Segundo o anuário estatístico do Alto Comissariado das Nações Unidas para os Refugiados de 2016, além do número histórico de indivíduos forçados a se mudar, há também um total de 22,5 milhões de refugiados em todo o mundo, 10 milhões de pessoas sem país onde se estabelecer, e um total de 189,300 refugiados recebidos por outros países. O país que

\footnotetext{
15 Disponível em <https://www.government.se/articles/2017/02/facts-about-migration-and-crime-in-sweden/>. Acessos em 14 jun. 2018.

16 Disponível em <https://www.government.se/articles/2018/04/central-government-budget-in-figures/>. Acessos em 14 jun. 2018.

${ }^{17}$ Disponível em <http://www.unhcr.org/figures-at-a-glance.html>. Acessos em 14 jun. 2018.
} 
mais hospedou refugiados foi a Turquia, que acolheu um total de 2,5 milhões de pessoas, seguida do Paquistão (1,4 milhão) e Líbano (1 milhão). ${ }^{18}$

O neoconservadorismo, determinante da política externa de George W. Bush e Ronald Reagan, possui uma grande influência no cenário instituído internacionalmente no que diz respeito ao crescente desequilíbrio entre as nações e à indeterminação do cenário político global. Há que se concordar que o sentimento instituído após a Guerra Fria é o de hegemonia da nação norte-americana sobre a comunidade internacional. Ocorre que, segundo o pensamento neoconservador absorvido pelo Estado e sociedade americanos, não basta apenas a predominância econômica da nação, mas a verdadeira instauração da política intervencionista típica de um Estado supremo, que adota as medidas necessárias para ganhar seu espaço entre os demais.

Além disso, este modelo é capaz de aliar à política intervencionista o pensamento nacionalista, fundado na unidade do povo norte-americano e na soberania de sua nação. Este entendimento, quando somado a uma economia e exército dos mais poderosos do mundo, gera solo fértil à discricionariedade dos Estados Unidos nos assuntos internacionais de seu interesse, sendo então fácil o confronto com nações economicamente desejáveis ou ao menos militarmente menos poderosas.

Entretanto, há que se notar que não é o neoconservadorismo destrutivo por si só. Este configura uma vertente filosófica, que como qualquer outra corrente, pode ou não ser adotada por líderes politicamente. Opera da mesma maneira o nacionalismo, que visa a unidade nacional, valorizando as riquezas culturais e especificidades históricas de determinado povo, não necessariamente submetendo outro povo a seu comando, como ocorrido na Segunda Guerra Mundial. Para Harari:

\begin{abstract}
Nacionalistas liberais como Mazzini buscaram proteger essas experiências nacionais distintivas da opressão e da obliteração impostas por impérios intolerantes e vislumbraram uma comunidade pacífica de nações, cada uma livre para expressar e explorar seus sentimentos comunitários sem ferir os de seus vizinhos. Essa é ainda a ideologia oficial da União Europeia, cuja Constituição de 2004 declara que a Europa está "unida na diversidade" e que os diferentes povos do continente permanecem "orgulhosos de suas identidades nacionais". O valor da preservação das experiências comunitárias exclusivas da nação alemã faculta a que alemães liberais se oponham à abertura das comportas da imigração $(2015$, p. 222).
\end{abstract}

Ao contrário da Segunda Guerra, que foi movida por ideologias deterministas e pensamentos pseudocientíficos, a guerra que se vive atualmente opera em função do

\footnotetext{
${ }^{18}$ Disponível em <https://www.unhcr.org/statistics/country/5a8ee0387/unhcr-statistical-yearbook-2016-16thedition.html>. Acessos em 10 ago. 2018.
} 
desenvolvimento econômico, este último sempre idealizado sob o viés do desenvolvimento infinito. ${ }^{19} \mathrm{O}$ objetivo, portanto, é crescer, não importando às custas de quê ou de quem. Por consequência, o resultado prático das intervenções, embora camuflado como urgência de estabelecimento da paz e da democracia, é a difusão dos valores de uma nação e o fortalecimento de sua economia em detrimento de outra. Ainda em consonância com o pensamento de Harari:

(...) Se a economia não crescer, e consequentemente a torta permanecer do mesmo tamanho, só se poderia dar mais aos pobres tirando algo dos ricos. Isso obrigaria a que se fizessem escolhas muito duras, e provavelmente causaria muito ressentimento e até violência. Para evitar tais escolhas, o ressentimento e a violência, precisa-se de uma torta maior (2015, p. 181).

Entretanto, o pensamento sobre a necessidade de se progredir não é por si só justificável. Ele necessita de fundamentos para se concretizar, e estes fundamentos devem ser, em essência, inabaláveis, a ponto de não suscitar dúvidas sobre sua legitimidade. Deve ser superior à liberdade de outras nações, para que estas aceitem sua inferioridade, ou ainda forneçam insumos ao crescimento da economia estrangeira. Para tanto, descarta-se o outro, inverte-se a realidade e submete-se o povo local aos desejos do invasor.

Eis a importância da promoção do terror para aniquilar as subjetividades, tornando as massas absolutamente homogêneas. O medo é, assim, o mecanismo mais eficaz contra a lógica, visto que é essencialmente uma reação automática de proteção, visando garantir a sobrevivência. Mas não há terror sem algo que o produza sobre os demais; para tanto, faz-se necessária a produção de um alvo sob o qual incidirá toda a fúria de uma nação desgovernada e amedrontada: a esse espetáculo se dá o nome de verdade, cujo monopólio se concentra nas mãos dos detentores do poder. Em muito colabora o pensamento de Debord, com sua definição do espetáculo sobre as massas:

O espetáculo apresenta-se como algo grandioso, positivo, indiscutível e inacessível. Sua única mensagem é "o que aparece é bom, o que é bom aparece". A atitude que ele exige por princípio é aquela aceitação passiva que, na verdade, ele já obteve na medida em que aparece sem réplica, pelo seu monopólio da aparência (2003, p. 17).

\section{Os avanços e retrocesso em Direitos Humanos no novo milênio}

\footnotetext{
${ }^{19}$ Método de crescimento econômico incapaz de agregar a si próprio a observância à limitação dos recursos nãorenováveis e a permanente degradação da biosfera.
} 
Conforme o cenário de instabilidade política tem afetado grande parte da Europa e inclusive as américas nos últimos anos, com um crescente fortalecimento de partidos e candidatos considerados de extrema direita, há que se notar também as transformações na forma como é realizada a política do país que dita as regras da comunidade internacional.

Donald Trump, presidente dos Estados Unidos é eleito em 2017, após uma disputa histórica com a candidata adversária, Hillary Clinton. Com o enfraquecimento dos Democratas, somado ao argumento de choque em relação à mídia e à imagem construída de um Outsider na política americana, destinou-se o então candidato a renovar a sociedade americana e dar novamente a ela o brilho que outrora possuiu.

O discurso sedutor motivou políticos de outras partes do planeta, que por sua vez passaram a adotar os mesmos argumentos, sempre fundamentados na fraqueza dos valores nacionais, no alarmismo e no discurso agressivo firmado contra o inimigo. Os resultados dessa iniciativa relativamente rebelde são impactantes, à medida que fragilizam grupos em situações delicadas.

No governo americano, além da construção do que se pode denominar de Grande Muralha da América, destinada a separar a população indesejada vinda do México, houve ainda um controle de imigração mais rígido nas fronteiras. No entanto, embora a medida tenha sido mais dura por parte do governante, a partir do início da gestão Trump houve uma significativa queda no número de deportações.

Em contrapartida, não necessariamente a queda pode ter ocorrido por conta de uma má-gestão no controle de fronteiras. Uma possível explicação para o fenômeno é justamente o desestímulo, por parte dos imigrantes, em deslocar-se ao país sob a nova administração, potencialmente mais rígida em relação a imigrantes em situação ilegal.

Na Europa, os movimentos migratórios foram em grande parte abalados pelo governo da Primeira Ministra Theresa May, que se tornou particularmente conhecido pelo referendo que deu fim à participação do Reino Unido na União Europeia. Embora tenha havido queda no período de 2016, quando o referendo foi assinado, o número de imigrações ao país voltou a crescer em 2017. ]Embora ambos o Reino Unido e os Estados Unidos tenham particularidades que dificultem a comparação dos fenômenos migratórios, pode-se ter, como meio meramente ilustrativo destes fluxos, uma certa relação entre as nações. Welzer, mesmo antes do ápice da crise humanitária, já descrevia o fenômeno:

Tanto a Europa como os Estados Unidos, em sua condição de países que apresentam o maior grau de atração tanto para refugiados como para imigrantes ilegais, seguem estratégias semelhantes, pelo menos em dois aspectos, para garantir a segurança de 
suas fronteiras. Por um lado, as medidas de contenção nas fronteiras e o pessoal que trabalha na manutenção da segurança vêm sendo progressivamente reforçados; por outro, existe uma tendência em ambos os pontos para tentar afastar o problema para além de suas fronteiras, se bem que esta tendência seja muito mais forte na União Europeia que nos Estados Unidos (2010, p. 166).

Os fluxos migratórios, no entanto, constituem um fenômeno de não apenas uma origem. Uma das principais questões que podem ser pontuadas, e que constitui um massivo propulsor dos fluxos migratórios é o cenário de guerra instituído no Oriente Médio em nome da democracia, além de especificidades geográficas. Ademais, as mudanças climáticas, amplificadas pelo aquecimento global e o ceticismo do homem quanto a seus impactos no ambiente, tendem a tornar cada vez mais escassos os recursos naturais em diversas localidades do planeta. (WELZER, 2010)

O Irã, por exemplo, é um país cuja migração também se destina ao território sueco, e que constitui, de forma declarada, uma ameaça à segurança nacional americana, conforme determina a Estratégia Militar Nacional. Entre guerras econômicas e assassinatos de cientistas atômicos (BANDEIRA, 2016), os Estados Unidos, na gestão Obama, causou profundos impactos aos iranianos, que podem com certeza refletir-se no fenômeno migratório. No entanto, conforme Moniz Bandeira, este não é o único país afetado:

Assim, o fato foi que, além da ameaça do terror, todas as dificuldades que a Itália, Espanha, França, Grã-Bretanha, Alemanha e Espanha e demais países da União europeia tiveram e têm de enfrentar, em consequência da migração de milhões de refugiados e pessoas deslocadas, devem-se principalmente às guerras que os Estados Unidos promoveram e a União Europeia, subordinada à OTAN, apoiou, instigou e/ou sustentou no Afeganistão, Iraque, na Síria, Líbia e em outros países da Ásia Central e Oriente Médio à África do Norte (2016, p. 163).

Sabe-se, há muito, que diversos dos conflitos nesses locais se dão, sobretudo, devido à abundância de recursos naturais de interesse das potências econômicas e bélicas, que ditam as regras na nova ordem mundial. Assim, não se poupam esforços quando o interesse é o fomento econômico à extração desses mesmos recursos, amparado pela comunidade internacional detentora do poder de voz.

O poderio da nova ordem mundial encontra-se, pois, no domínio de tudo o que é palpável e não palpável. Domina-se toda a forma de energia, seja ela intelectual ou material, visando a subserviência ao modelo instituído. O controle desses mesmos mecanismos de poder é o que determina as regras de manutenção da realidade capitalista, auferindo força aos que servem, mas não em demasia, para que não se insurjam, e retirando dos inimigos tudo quanto o que lhes cabe perder. 
No caso do Oriente Médio, lhes coube ter energia alienada. Fala-se do petróleo, rico na região, que foi tomado pelos interesses americanos em se apropriar do recurso, eliminando a concorrência e ditando o preço do óleo ao valor que lhe aprouver. O capitalismo, assim, encontra formas escusas de manutenção, fortalecendo o entendimento de que uma nova guerra mundial se institui, aniquilando os países emergentes potencialmente ameaçadores, e privando os pequenos da ascensão no cenário global.

É, portanto, a urgência de privar do homem sua liberdade que determina quem são os vencedores do conflito. Aquele que mais nações subjugar, possuirá influência suficiente para modular as relações internacionais de forma benéfica aos próprios interesses. A lógica da alienação determina o rumo do processo, sendo fundamental o silêncio, e suprimida qualquer forma de revolução.

Os recursos naturais teriam então esse condão de autoridade sobre o destino, onde seu proprietário promove o absurdo em nome da democracia, cria inimigos entre as nações e deixa que se digladiem até que nada mais reste. A insurgência ao modelo instituído deve ser impensável ou até mesmo impossível, pois não se aceita outra alternativa que não a realidade. Conforme Graziano (2005):

Controlar a energia é ter o poder. Se os mais importantes recursos energéticos são escassos e não renováveis, como o petróleo e o gás, os que controlarem esses bens terão o poder. Se as principais fontes de energia se baseassem em recursos renováveis - e é preciso levar em conta que toda matéria é fonte potencial de energia -, nenhum minúsculo grupo poderia deter o poder, porque as decisões humanas de consumo poderiam muito bem ficar muito mais independentes da necessidade de trabalhar (2005, p. 42).

Ocorre que, além das guerras ocasionadas em virtude destes mesmos recursos naturais, sua extração e a atividade econômica criam um inimigo superior à força das nações, ainda que por elas negado. O câmbio climático tem resultado em inúmeras perdas à humanidade, não apenas em questões ecossistêmicas e de biodiversidade, como também no que concerne à dignidade humana. $\mathrm{O}$ aumento das temperaturas globais ${ }^{20}$ é, assim, um dos fatores que determinam o destino de milhões de famílias ao redor do mundo, que abandonam seus lares para uma vida semelhante ao nomadismo, buscando locais mais apropriados para se reestabelecer. Leciona Welzer:

Paradoxalmente, tais perspectivas infelizes se tornam ainda mais graves quando a nação possui grandes recursos naturais, como diamantes, petróleo ou madeira-de-lei. A "praga das matérias-primas" a torna particularmente atraente para o saque da parte

\footnotetext{
${ }^{20}$ Disponível em <https://climate.nasa.gov/vital-signs/global-temperature/>. Acessos em 10 ago. 2018
} 
dos intermediários da violência nacionais e internacionais. As guerras civis ou crises de violência semelhante à das guerras civis rapidamente começam a grassar, em particular quando existem nichos e pontos de apoio - espaços abertos para a violência - em que tanto o crime organizado ou o terrorismo internacional possam construir suas bases - como já é o caso da Somália (2010, p. 80).

\subsection{A situação dos povos sem-nação em território sueco}

O fluxo migratório relativo ao cenário sueco é composto de países oriundos sobretudo do Oriente médio, totalizando estes, do período de 200 a 2016, 43\% do total de inscritos à concessão de asilo no país. São os países Síria (17\%), Iraque (13\%), Afeganistão (10\%) e Irã (3\%). Os indivíduos sem Estado compõem 6\% do volume de solicitantes de asilo no local. A Suécia, passou a ser, assim, o país com maior número de imigrantes per capita da Europa. ${ }^{21}$

Embora o contexto atual dos imigrantes seja reflexo de conflitos de longa data, no novo milênio o fenômeno se intensifica, seguindo as tendências estratégicas das potências mundiais em desenvolvimento e geopolítica. Os arsenais nucleares, por sua vez, possuem um papel central no processo, devido a seu alto poder coercitivo sobre os países sem o mesmo potencial bélico.

Os grupos neonazistas suecos, embora rechaçados pelo Parlamento e também pelo sistema judiciário nacional, têm ganhado maior visibilidade nos últimos tempos, e isto se dá sobretudo ao discurso alarmista que visa atribuir responsabilidade aos refugiados e imigrantes sobre o fracasso do governo sueco em lidar com a política migratória previamente instituída. No entanto, diga-se seletiva, a discriminação. Não são todos os grupos que são atingidos pelo discurso de ódio, tendo em vista que outras populações europeias e ocidentais não são especialmente malvistas pela população.

O que existe e se intensifica, é o discurso de ódio baseado em critérios fenotípicos, culturais e religiosos, que são estranhos à sociedade sueca. Logicamente, é evidente que um acentuado movimento migratório pode suscitar inúmeras questões de ordem social. No entanto, é dever do Estado estar preparado às adversidades, e fazer cumprir os valores constitucionais.

Para tanto, não apenas se deve fornecer abrigo aos refugiados e imigrantes que atravessam as fronteiras em precárias condições. A sociedade como um todo deve estar preparada para lidar com os novos integrantes, sendo fundamental a tomada de medidas que garantam a conscientização da população sobre o respeito às diferenças.

\footnotetext{
${ }^{21}$ Disponível em <https://www.usatoday.com/story/news/world/2017/04/12/swedes-wonder-after-terror-attackwe-too-welcoming-migrants/100334226/>. Acessos em 07 de agosto de 2018
} 
Deve se ressaltar que a comunidade internacional como um todo deve ser responsabilizada pelo massacre dessas populações, que morrem aos milhares no processo de travessia entre os países. No entanto, incumbe aos Estados em particular fazer valer os valores ora atribuídos durante a assinatura de tratados de direitos humanos, além do conteúdo constitucionalmente previsto.

Seria pontual que o governo promovesse medidas de capacitação profissional aos imigrantes, integrando verdadeiramente esses povos à comunidade, em vez de conjugar esforços de forma a repeli-los do território. De fato, devem-se preservar os valores culturais e históricos de um povo, mas também deve se levar em consideração que estes se modulam em função da realidade, não sendo, portanto, imutáveis.

\section{Considerações Finais}

Entende-se o aumento do fluxo migratório como produto da nova ordem mundial instituída, liderada pelos Estados Unidos da América em seu processo de conquista do cenário global, tanto no aspecto político quanto econômico. A busca pela imposição, nos países menos favorecidos, de modelos de organização social fundados sobretudo no estilo de vida ocidental e em sua estrutura sociopolítica, constitui um grave atentado ao equilíbrio da comunidade internacional.

Ditar, portanto, os valores do correto e do ideal, é uma prática tão destrutiva quanto a guerra em sua essência, que por sua vez pouco tem a ver com a defesa dos povos oprimidos pelo regime de seu país. Em verdade, a guerra se impulsiona pelo motor econômico global, cujos anseios pelo progresso infinito ocupam grande parte da agenda das potências globais.

Embora o contexto atual dos imigrantes seja reflexo de conflitos de longa data, no novo milênio o fenômeno se intensifica, seguindo as tendências estratégicas das potências mundiais em desenvolvimento e geopolítica. Os arsenais nucleares, por sua vez, possuem um papel central no processo, devido a seu alto poder coercitivo sobre os países sem o mesmo potencial bélico.

Assim, assumir os reflexos da globalização é um grande passo que precisa ser dado no que tange o cumprimento das responsabilidades assumidas internacionalmente. Ao romper as barreiras da comunicação, novos compromissos devem ser levados em consideração para atender as necessidades populares, que se intensificam conforme a conduta dos Estados internacionalmente. Estes compromissos deverão ser assumidos não somente pelos países que percebem o fenômeno migratório, como também pelos que o promovem. 


\section{Referências}

ASSEMBLEIA GERAL DA ONU. Carta das Nações Unidas e Estatuto da Corte Internacional de Justiça. Paris: Organização das Nações Unidas, 1945.

Unidas, 1948

Declaração Universal Dos Direitos Humanos. Paris: Organização das Nações

Report of the Special Rapporteur on the rights of indigenous peoples on the human rights situation of the Sami people in the Sápmi region of Norway, Sweden and Finland. Paris: Organização das Nações Unidas, 2016.

BANDEIRA, Luiz Alberto Moniz. A Desordem Mundial: O espectro da total dominação. Rio de Janeiro: Civilização Brasileira, 2016.

As políticas neoliberais e a crise na América do Sul. In: Rev. bras. polít. int., Brasília, v. 45, n. 2, p. 135-146, Dez. 2002. Disponível em $<$ http://www.scielo.br/scielo.php?script=sci_arttext\&pid=S0034$73292002000200007 \& \operatorname{lng}=$ en\&nrm=iso $>$. Acessos em 14 jun. 2018.

BERGH, Andreas, The Rise, Fall and Revival of the Swedish Welfare State: What are the Policy Lessons from Sweden? IFN Working Paper, n. 873, jul. 2011. Disponível em $<$ https://ssrn.com/abstract=1884528>. Acessos em 14 jun. 2018.

BLYTH, Mark. Austerity: the history of a dangerous idea. Nova Iorque: Oxford University Press, 2013.

BRESSER-PEREIRA, Luiz Carlos. Assault on the State and on the market: Neoliberalism and economic theory. Estud. av., São Paulo, v. 23, n. 66, p. 7-23, 2009. Disponível em $<$ http://www.scielo.br/scielo.php?script=sci_arttext\&pid=S0103$40142009000200002 \& \operatorname{lng}=$ pt\&nrm=iso > . acessos em 14 jun. 2018.

BUNAR, Nihad. Hate Crimes Against Immigrants in Sweden and Community Responses. In: American Behavioral Scientist. California: SAGE Publications, v. 51 n. 2, 2007. pp. 166-181.

CASADO FILHO, Napoleão. Direitos Humanos Fundamentais. São Paulo: Saraiva, 2012.

DEBORD, Guy. The Society of the Spectacle. Cambridge: MIT Press, 2003.

ESTADOS UNIDOS DA AMÉRICA. Sweden 2016 Human Rights Report. Washington: Department of State, 2016.

FANON, Frantz. Os Condenados da Terra. Rio de Janeiro: Editora Civilização Brasileira S.A., 1968.

HARARI, Yuval N. Homo Deus: uma Breve História do Amanhã. Tradução de Paulo Geiger. São Paulo: Editora Schwartz S.A., 2015.

HAYEK, Friedrich A. Individualism and Economic Order. Auburn: Ludwig von Mises Institute, 2009. 
MORIN, Edgar. Ética, Cultura e Educação. São Paulo: Cortez, 2001.

POMBO, Olga. Interdisciplinaridade e integração dos saberes. Liinc em revista. Rio de Janeiro, v. 1, n. 1, p. 1-13, set. 2005.

SANANDAJI, Nima. The Swedish Model Reassessed - Afluence despite the welfare state. Libera Foundation: Helsinki, out. 2011. Disponível em <http://libera.fi/wpcontent/uploads/2013/05/Libera_The-Swedish-model.pdf>. accessos em 14 jun. 2018.

SANDBERG, Jessica. Human Rights in Sweden. In: Revista IIDH. San José: O Instituto, vol. 36, 2002. pp. 107-127.

SUÉCIA. Crime among persons born in Sweden and other countries. Stockholm: Brottsförebyggande rådet, 2009.

. Constitutional Documents of Sweden: The Instrument of Government, the Riksdag Act, the Riksdag Regulations. Stockholm: Swedish Riksdag, 1972.

Facts About Sweden: Monarchy. Estocolmo: Swedish Institute, 2016

Facts about migration, integration and crime in Sweden. Stockholm, 2018. Disponível em <https://www.government.se/articles/2017/02/facts-about-migration-andcrime-in-sweden/>. acessos em 28 ago. 2018.

. Sweden in the EU. Stockholm: Sveriges Riksdag, 2011.

. The Swedish Judicial System. Stockholm: Regeringskansliet, 2015.

TIBURI, Marcia. Como Conversar com um Fascista. Rio de Janeiro: Record, 2016. 5.ed.

WELZER, Harald. Guerras Climáticas: por que mataremos e seremos mortos no Século 21. São Paulo: Geração Editorial, 2010.

WOLKMER, Antonio Carlos; LIXA, Ivone Fernandes M. Constitucionalismo, Descolonización y Pluralismo Jurídico em América Latina. In: Aguascalientes: CENEJUS / Florianópolis: UFSC-NEPE, 2015. 